\title{
A gratuidade da justiça e a nova ordem constitucional $^{*}$
}

\section{Gratuity of justice and the new constitutional order}

\section{Resumo}

Tendo em vista os entendimentos judiciais que ainda persistem em dificultar o acesso à justiça, indeferindo o pedido de gratuidade, o presente artigo busca demonstrar a visão adequada da gratuidade da justiça diante da Constituição Federal.

Palavras-chave: Acesso à justiça. Gratuidade. Constituição Federal.

\begin{abstract}
In view of judicial understandings that persist in barring access to justice, rejecting the application for gratuity, this article seeks to demonstrate adequate vision of the gratuitousness of justice before the Federal Constitution.
\end{abstract}

Keywords: Access to justice. Gratuitousness. Federal Constitution.

\footnotetext{
* Artigo recebido em julho de 2012. Aprovado em agosto de 2012.

1 Advogado e Professor Universitário. Pós-graduado em Função Social do Direito (UNISUL/ LFG). Autor dos livros "Crimes Contra a Vida" (Ed. Memória Jurídica) e "Responsabilidade Civil: compensar, punir e educar" (Ed. Memória Jurídica). Autor de diversos artigos jurídicos publicados.
} 
Não são raras as decisões judiciais que indeferem a concessão da gratuidade da justiça pelos mais variados motivos, sendo a mais comum, a não recepção pela Constituição Federal do art. 4º da Lei 1060/50.

Prescreve o referido dispositivo legal:

Art. 4 A parte gozará dos benefícios da assistência judiciária, mediante simples afirmação, na própria petição inicial, de que não está em condições de pagar as custas do processo e os honorários de advogado, sem prejuízo próprio ou de sua família.

Entretanto, mesmo realizando uma rápida leitura do dispositivo supra, verifica-se que ele foi sim recepcionado pela Constituição Federal de 1988, pois claramente visa assegurar a todos o acesso à justiça, observando o princípio da inafastabilidade do controle jurisdicional.

Se o Constituinte de 1988 não pretendesse recepcionar o art. $4^{\circ}$ da Lei 1060/50, certamente não teria incluído em nossa Carta Magna os incisos XXXV e LXXIV do art. $5^{\circ}$.

Vejamos os incisos:

XXXV - a lei não excluirá da apreciação do Poder Judiciário lesão ou ameaça a direito.

LXXIV - o Estado prestará assistência jurídica integral e gratuita aos que comprovarem insuficiência de recursos.

Ainda que não existisse o inciso LXXIV, pensamos que o acesso à justiça estaria plenamente garantido diante do inciso XXXV do art. $5^{\circ}$, que consagra inequivocamente o princípio da inafastabilidade do controle jurisdicional; logo, não há como excluir da apreciação do Judiciário qualquer lesão ou ameaça a direito, ou seja, o pedido de gratuidade da justiça não pode ser óbice contra a parte que o pleiteia, pois se há lesão ou ameaça de lesão, cabe ao Poder Judiciário pronunciamento jurisdicional, não podendo ele impor obstáculo, indeferindo sumariamente pedido de gratuidade quando a parte alega não poder arcar com as custas processuais.

O pedido de gratuidade da justiça tem respaldo no princípio constitucional da inafastabilidade do controle jurisdicional, insculpido no art. $5^{\circ}$ inciso XXXV da Lei Maior.

Nesse diapasão, ensina Dirley da Cunha Júnior:²

2 CUNHA JÚNIOR, Dirley da. Curso de direito constitucional. 4. ed. Salvador: Juspodivm, 2010, p. 699.
O direito de acesso à justiça traduz-se numa das maiores conquistas do Estado Democrático de Direito. Manifesta-se pela inafastável prerrogativa de provocar a atuação do Poder Judiciário para a defesa de um direito.

Em conformidade com a Constituição, a lei não excluirá da apreciação do Poder Judiciário lesão ou ameaça a direito (art. 5 XXXV). Proclamou, com isso, a garantia da inafastabilidade da jurisdição, com o que proibiu qualquer lei ou ato limitar o acesso ao Judiciário.

Ainda sobre o princípio da inafastabilidade do controle jurisdicional, há de ser transcrito o trecho do brilhante voto do eminente Relator Ministro Hélio Quaglia Barbosa no julgamento do Recurso Especial $n^{\circ}$ 848.152-RS:

Vale salientar que a qualquer tempo, é lícito às partes requerer o benefício, independentemente de comprovação, bastando, para tanto a simples assertiva de que não pode prover as custas do processo, sem prejuízo próprio ou de sua família. Por derradeiro, quadra ressaltar que deve ser respeitado o princípio da inafastabilidade do controle jurisdicional, na medida em que, por vezes, a parte que requer os auspícios não possui condições financeiras de arcar com as custas e despesas acarretados pelo trâmite regular de um processo, sem prejuízo próprio e/ ou de sustento de sua própria família, devendo o magistrado, em tais situações, pautar-se sempre de acordo com o senso de justiça, cuja essência recomenda que se dê preferência ao princípio que veda o impedimento do acesso à jurisdição. (grifo nosso).

Verifica-se que restrições ao acesso à justiça encontram no princípio da inafastabilidade seu obstáculo; logo, no caso do pedido de gratuidade da justiça, basta a simples assertiva das partes no sentido de não poder prover as custas processuais sem causar prejuízo ao sustento próprio e/ou da família para a concessão do benefício.

Não temos dúvidas em afirmar que o art. $4^{\circ}$ da Lei 1060/50 foi recepcionado pela Nova Ordem Constitucional; logo, basta a afirmação da parte de não poder arcar com as custas processuais sem prejuízo próprio e/ou de sua família, para a concessão do benefício, pois certo é que cabe à parte contrária impugnar a concessão da gratuidade.

Nesse sentido, já se manifestou o Egrégio Tribunal de Justiça do Estado de São Paulo:

EMENTA: Basta a afirmação de pobreza para a concessão do benefício da gratuidade judiciária. Presunção só ilidida por eventual prova feita pela parte contrária. Recepção do artigo $4^{\circ}$ da 
lei 1060/50 pela Constituição Federal. Agravo provido para conceder a gratuidade judiciária à agravante. ${ }^{3}$

EMENTA: AGRAVO DE INSTRUMENTO ACIDENTE/ SEGURO DE VEÍCULO - INDENIZAÇÃO - BENEFÍCIOS DA ASSISTÊNCIA JUDICIÁRIA GRATUITA DECLARAÇÃO DE POBREZA - SIMPLES AFIRMAÇÃO DOS AGRAVANTES DE QUE NÃO TÊM CONDIÇÕES DE ARCAREM COM AS CUSTAS E DESPESAS DO PROCESSO - SUFICIÊNCIA - PARTE CONTRÁRIA QUE DEVE IMPUGNAR OS BENEFÍCIOS DA ASSISTÊNCIA JUDICIÁRIA GRATUITA - CONTRATAÇÃO DE ADVOGADO QUE NÃO IMPLICA, POR SI SÓ, EM POSSIBILIDADE DE ARCAR COM AS CUSTAS - RECONHECIMENTO. Agravo de Instrumento provido. ${ }^{4}$

EMENTA: Basta a afirmação de pobreza para a concessão do benefício da gratuidade judiciária. Presunção só ilidida por eventual prova feita pela parte contrária. Recepção do artigo $4^{\circ}$ da lei 1060/50 pela Constituição Federal. Agravo provido para conceder a gratuidade judiciária à agravante. ${ }^{5}$

Quanto à declaração da parte, deve ser destacado que há presunção de veracidade da afirmação feita pela parte postulante e que só pode ser afastada com a impugnação da parte contrária comprovando que as circunstâncias reais demonstram que o benefício não deve remanescer.

Nesse sentido, também é o entendimento do Tribunal de Justiça do Estado de São Paulo:

Ementa: - A todo tempo e mediante simples declaração dá-se a qualquer dos litigantes pedir o benefício da assistência judiciária gratuita, que só não se defere se as circunstâncias desmentirem a alegação de pobreza - Cobrança de condomínio - Fase de execução da sentença - A Lei $n^{\circ} 11232 / 05$, processual que é, tem incidência imediata, inclusive sobre os processos em curso, respeitando-se, claro, os atos já praticados sob a vigência da lei anterior - Hipótese em que não há atos de execução praticados na vigência da lei anterior a serem preservados - Citação realizada sem observância da norma vigente - Anu-

\footnotetext{
3 Agravo de Instrumento $\mathrm{n}^{\circ} 00179824720118260000$. Relator: Soares Levada Órgão julgador: $34^{\text {a }}$ Câmara de Direito Privado Data do julgamento: 28/02/2011. Data de registro: 04/03/2011.

4 Agravo de Instrumento 1270539000. Rel. Des. Jayme Queiroz Lopes. 36a Câmara de Direito Privado. Data do Julgamento: 28/05/2009.

5 Agravo de Instrumento no 00036446820118260000 Relator: Soares Levada. Órgão Julgador $34^{\mathrm{a}}$ Câmara de Direito Privado. Data do Julgamento 14/02/2011. Data de Registro 25/02/2011. (grifo nosso).
}

lação - Aplicabilidade ao caso do art 475-J do CPC - Agravo provido. ${ }^{6}$

EMENTA: Agravo de Instrumento. Assistência Judiciária Gratuita. Impossibilidade de pagar as custas do processo e honorários de advogado. Presunção de veracidade da afirmação feita pela parte. Recurso provido. ${ }^{7}$

EMENTA: A todo tempo e mediante simples declaração dá-se a qualquer dos litigantes pedir o benefício da assistência judiciária gratuita, que, porém, não se defere se as circunstâncias desmentirem a alegação de pobreza. ${ }^{8}$

Destarte, verifica-se que, diante da alegação, no momento não há como a parte prover as custas processuais sem prejuízo de seu sustento e/ou de sua família, é o suficiente para a concessão do benefício, ressalvado os casos em que as circunstâncias demonstram claramente que a parte pode arcar com as despesas processuais.

Não se deve olvidar que a Lei 7115/83 em seu art. $1^{\circ}$ dispõe que "A declaração destinada a fazer prova de vida, residência, pobreza, dependência econômica, homonímia ou bons antecedentes, quando firmada pelo próprio interesse ou por procurador bastante, e sob as penas da Lei, presume-se verdadeira”. Logo, constata-se que o indeferimento da gratuidade sem fundamento válido ignora o referido dispositivo.

Imprescindível asseverar que o termo "pobreza" do art. $1^{\circ}$ da Lei $7115 / 83$ deve ser compreendido como impossibilidade de arcar com as custas processuais, pois a Constituição Federal e a Lei 1060/50 não exigem que o postulante seja pobre na acepção jurídica do termo, o que se exige é que afirme não estar em condições de pagar as custas do processo sem causar prejuízo ao sustento próprio e/ou de sua família. Diga-se o mesmo sobre a expressão “pobre" do $₫ 1^{\circ}$ do art. $4^{\circ}$ da Lei 1060/50.

A Lei 1060/50 em seu art. $2^{\circ}$ é clara ao dispor que:

Gozarão dos benefícios desta Lei os nacionais ou estrangeiros residentes no país, que necessitarem recorrer à Justiça penal, civil, militar ou do trabalho, sendo

6 Agravo de Instrumento 1234545007. Rel. Des. Silvia Rocha Gouvêa. 28 ${ }^{\text {a }}$ Camara de Direito Privado. Data do Julgamento: 26/05/2009.

7 Agravo de Instrumento 1270968002 Rel. Des. Pedro Baccarat. $36^{\text {a }}$ Câmara de Direito Privado. Data do Julgamento 28/05/2009.

8 Agravo de Instrumento 1267966002. Rel. Silvia Rocha Gouvêa. 28 ${ }^{\text {a }}$ Câmara de Direito Privado. Data do Julgamento: 26/05/09). 
certo que em seu parágrafo único, considera necessitado para fins legais todo aquele cuja situação econômica não lhe permita pagar as custas do processo e os honorários de advogado, sem prejuízo do sustento próprio ou da família.

Ora, fica claro que não há necessidade da parte postulante estar literalmente na miséria para que o benefício da gratuidade seja concedido, pois o que se exige é que a sua situação econômica atual não lhe permita arcar com as despesas processuais.

Mister asseverar que a Constituição Federal e a Lei 1060/50 não colocaram qualquer restrição à parte que postule a concessão da gratuidade da justiça; logo, data vênia, não cabe ao julgador apresentar restrições que a Constituição Federal e Lei não fizeram, pois, agindo assim, estaria legislando e usurpando competência do Poder Legislativo. Diga-se novamente que a declaração da parte no sentido de impossibilidade de arcar com as despesas processuais presume-se verdadeira.

Aliás, diante do princípio constitucional da inafastabilidade do controle jurisdicional, o direito de ação não pode ser restringido da maneira alguma, sobretudo quando se apresenta legítimo fundamento para o pedido da gratuidade.

Assim aduz Rinaldo Mouzalas de Souza e Silva ${ }^{9}$ acerca do referido princípio:

\begin{abstract}
Este princípio é garantia do direito de ação, por conferir àquele que for ou que seja na iminência de ser lesado em seus direitos o acesso irrestrito ao Poder Judiciário, bem como ter a devida e a efetiva prestação da tutela jurisdicional. Dirigido tanto ao legislador, que fica impedido de lançar leis que restrinjam o amplo acesso aos órgãos do Judiciário, quanto ao juiz, que deve dar a correspondente e efetiva resposta à pretensão posta a sua apreciação. É a tábua que viabiliza o amplo e irrestrito acesso à justiça.
\end{abstract}

As consequências de uma decisão que indefere o pedido de justiça gratuita são manifestas, pois, não podendo a parte prover as custas processuais sem prejuízo de seu sustento, verá seu direito de ação praticamente fulminado em razão de restrição que a Lei não faz. Assim, é indiscutível que indeferir sumariamente a concessão do benefício coloca restrições que nem a Constituição Federal e nem a Lei 1060/50 apresentam.

9 SILVA, Rinaldo Mouzalas de Souza e. Processo civil. Salvador: Juspodivm, 2009, p. 26-27.
A Nova Ordem Constitucional demanda revisão de entendimentos que indeferem a concessão do benefício da gratuidade da justiça, pois, diante do princípio constitucional da inafastabilidade do controle jurisdicional e da assertiva da parte no sentido, de que não pode prover as custas processuais, milita uma presunção de veracidade a qual o magistrado não pode afastar de imediato (ressalvados os raríssimos casos em que as circunstâncias demonstram claramente $a b$ initio que a parte pode arcar com tais despesas), cabendo à parte contrária impugnar ou não a concessão do benefício.

Também não é possível colocar restrições como profissão ou local de residência do postulante, pois, o fundamento do pedido encontra-se na inafastabilidade do controle jurisdicional e as atuais condições financeiras do postulante; logo, restringir a concessão do benefício por tais fundamentos é colocar restrições que nem a Constituição Federal e nem a Lei 1060/50 apresentaram; e como já dito, tal ato representa usurpação da competência do Poder Legislativo.

Já decidiu o Egrégio Tribunal de Justiça do Estado de Minas Gerais:

EMENTA: AGRAVO DE INSTRUMENTO - BENEFÍCIOS DA ASSISTÊNCIA JUDICIÁRIA - DECLARAÇÃO FIRMADA NOS AUTOS - PRESUNÇÃO JURIS TANTUM DE VERACIDADE - PRINCÍPIOS DO ACESSO À JUSTIÇA E DA ASSISTÊNCIA JUDICIÁRIA INTEGRAL (CF, art. 5 XXXV e LXXIV) - RECURSO PROVIDO. A garantia fundamental de acesso à Justiça não pode ser preterida por questões decorrentes de exacerbado formalismo, porquanto esse instituto - de berço constitucional - não requer (e nem admite) exigências que possam desvirtuá-lo ou obstaculizar a sua efetivação. ${ }^{10}$

Ademais, a Lei 7115/83 é clara em seu art. $2^{\circ}$ sobre as consequências da falsidade da declaração feita pela parte "Se comprovadamente falsa a declaração, sujeitar-se-á o declarante às sanções civis, administrativas e criminais previstas na legislação aplicável”.

Em sede recursal, a parte que pretender postular a concessão da gratuidade poderá fazê-lo diretamente na instância superior, não havendo que se falar em falta de preparo. Nessa hipótese, ainda que negado na instância

\footnotetext{
${ }_{10}$ Agravo de Instrumento 1.0024.04.494670-5/004. Rel. Des. Nepomuceno Silva. 5a Câmara Cível. Data do Julgamento 04/12/2008.
} 
superior o pedido de gratuidade, não há que se falar em deserção, sendo necessária a concessão de prazo para o postulante recolher as custas devidas.

Nesse sentido, é a jurisprudência do Superior Tribunal de Justiça:

PROCESSUAL CIVIL. AÇÃO ORDINÁRIA DE NULIDADE CUMULADA COM CANCELAMENTO OU IMPEDIMENTO DE REGISTRO COM PEDIDO DE TUTELA ANTECIPADA. SENTENÇA. EXTINÇÃO DO PROCESSO. APELAÇÃO. DESERTA. PREPARO. NÃO RECOLHIDO. PEDIDO DE JUSTIÇA GRATUITA. PETIÇÃO INICIAL. EXAME. INOCORRÊNCIA. NECESSIDADE DE EXAME DA PRETENSÃO PELO TRIBUNALDE ORIGEM. PRESUNÇÃO DE CONCESSÃO. RECURSO ESPECIAL CONHECIDO E PROVIDO.

I. Feito pela recorrente pedido de assistência judiciária gratuita na petição inicial, e não tendo havido nenhum pronunciamento judicial a respeito da gratuidade, é defeso ao Tribunal estadual julgar deserta a apelação da parte sem antes analisar o seu pleito e, sendo o caso de indeferimento do benefício, deve ser aberto prazo para o recolhimento do preparo.

II. Recurso conhecido e provido. ${ }^{11}$

RECURSO ESPECIAL - EXECUÇÃO - TÍTULO EXTRAJUDICIAL - NEGATIVA DE PRESTAÇÃO JURISDICIONAL - OMISSÃO - NÃO-OCORRÊNCIA - PEDIDO DE ASSISTÊNCIA JUDICIÁRIA - INDEFERIMENTO - APELAÇÃO - DESERÇÃO -

MANIFESTAÇÃO DO TRIBUNAL ACERCA DO PEDIDO DE G RATUIDADE - NECESSIDADE - PRECEDENTES - RECURSO ESPECIAL PROVIDO.

I - Não havendo omissão no acórdão recorrido, mas somente entendimento contrário às pretensões do recorrente, não há se falar em negativa de prestação jurisdicional;

II - A falta do recolhimento do preparo da apelação não autoriza o Tribunal a decretar a deserção do recurso, sem que haja prévia manifestação acerca do pedido de gratuidade de justiça, que constitui o mérito do próprio apelo;

III - Caso o Tribunal de origem, mediante decisão fundamentada, manifeste-se contrariamente ao deferimento da assistência judiciária gratuita, deve possibilitar ao apelante a abertura de prazo para o pagamento do numerário correspondente ao preparo, que só ali se tornou exigível;

${ }^{11}$ Resp. 1043631/RS. Relator: Ministro Aldir Passarinho Junior. Quarta Turma. Data do Julgamento 26/05/09.
IV - Recurso especial provido. ${ }^{12}$

JUSTIÇA GRATUITA. Requerimento denegado na sentença. Apelação. Falta de preparo. Possibilidade. Interposta apelação da sentença que denegou o benefício da gratuidade, a falta de preparo não autoriza seja decretada a deserção do recurso do requerente do benefício sem que previamente seja examinada pela Câmara a questão da gratuidade; se denegada, será oportunizado ao requerente o pagamento do numerário correspondente ao preparo, que só ali se tornou exigível.

Recurso conhecido em parte e provido. ${ }^{13}$

RECURSO ESPECIAL - JUSTIÇA GRATUITA - REQUERIMENTO EM APELAÇÃO - DESERÇ̃̃O DO RECURSO - IMPOSSIBILIDADE -PAGAMENTO POSTERIOR - DECLARAÇÃO DE POBREZA FIRMADA POR ADVOGADO - PODERES ESPECIAIS - DESNECESSIDADE - RECURSO PROVIDO.

1 - O pedido de assistência judiciária gratuita pode estar embasada em declaração de pobreza firmada por advogado da parte com poderes para o foro em geral, não sendo necessário poderes específicos.

2 - A teor da jurisprudência desta Corte, sendo realizado o pedido de gratuidade da justiça em segundo grau, em caso de indeferimento deste, há que se oportunizar o pagamento posterior do preparo. Precedentes.

3 - Recurso provido para determinar que seja novamente apreciado o pedido de assistência judiciária gratuita e, em caso de indeferimento, que seja oportunizado à parte o pagamento do preparo. $^{14}$

$\mathrm{Na}$ análise do pedido de gratuidade da justiça, o magistrado, em hipótese alguma, pode afastar ou ainda restringir os dispositivos constitucionais insculpidos no art. $5^{\circ}$ (incisos XXXV e LXXIV), pois, o princípio da efetividade impõe ao intérprete a observância da vontade constitucional. Nesse sentido, ensina Luís Roberto Barroso: ${ }^{15}$

Efetividade significa a realização do Direito, a atuação prática da norma, fazendo prevalecer no mundo dos fatos os valores e interesses por ela tutelados. Simboliza, portanto, a aproximação, tão íntima quanto possível, entre o dever-

${ }^{12}$ REsp. 1087290/SP. Relator: Ministro Massami Uyeda. Terceira Turma. Data do Julgamento 05/02/09.

${ }^{13}$ REsp. 247428/MG. Relator: Ministro Ruy Rosado de Aguiar. Quarta Turma. Data do Julgamento 02/05/00.

${ }^{14}$ REsp. 731880/MG. Relator: Ministro Jorge Scartezzini. Quarta Turma. Data do Julgamento 20/10/05).

${ }^{15}$ BARROSO, Luís Roberto. Curso de direito constitucional contemporâneo. São Paulo: Saraiva, 2009, p. 305. 
ser normativo e o ser da realidade social. O intérprete constitucional deve ter compromisso com a efetividade da Constituição: entre interpretações alternativas e plausíveis, deverá prestigiar aquela que permita a atuação da vontade constitucional, evitando, no limite do possível, soluções que se refugiem no argumento da não auto-aplicabilidade da norma ou na ocorrência de omissão do legislador.

A gratuidade da justiça encontra amparo na Constituição Federal, sendo ainda prevista na Lei 1060/50, que, conforme visto, foi recepcionada pela nova ordem constitucional. Entendimentos em sentido contrário é que devem ser rechaçados, pois, eles representam obstáculo ao acesso à justiça.

\section{Referências}

BARROSO, Luís Roberto. Curso de direito constitucional contemporâneo. São Paulo: Saraiva, 2009.

CUNHA JÚNIOR, Dirley da. Curso de direito constitucional. 4. ed. Salvador: Juspodivm, 2010.

SILVA, Rinaldo Mouzalas de Souza e. Processo civil. Salvador: Juspodivm, 2009. 